This document is confidential and is proprietary to the American Chemical Society and its authors. Do not copy or disclose without written permission. If you have received this item in error, notify the sender and delete all copies.

\title{
Influence of the AOT counterion chemical structure in the generation of organized systems
}

\begin{tabular}{|r|l|}
\hline Journal: & Langmuir \\
\hline Manuscript ID & la-2020-01575w.R2 \\
\hline Manuscript Type: & Article \\
\hline Complete List of Authors: & n/a \\
\hline & $\begin{array}{l}\text { Lépori, Cristian M.O.; CONICET Cordoba, Instituto de Física Enrique } \\
\text { Gaviola (IFEG) } \\
\text { Co Química } \\
\text { Silber, Juana; Universidad Nacional de Rio Cuarto, Quimica } \\
\text { Falcone, R. Dario; Universidad Nacional de Rio Cuarto, Quimica } \\
\text { López-López, Manuel; Universidad de Huelva, Departamento de } \\
\text { Ingeniería Química, Química Física y Química } \\
\text { Moyá, María Luisa; Universidad de Sevilla, Department of Physycal } \\
\text { Chemistry }\end{array}$ \\
\hline
\end{tabular}




\title{
Influence of the AOT counterion chemical
}

\section{structure in the generation of organized systems}

\author{
Cristian M. O. Lépori*[a] N. Mariano Correa ${ }^{[b, c]}$, Juana J. Silber ${ }^{[b, c]}$, R. Darío \\ Falcone $^{[b, c]}$, Manuel López-López ${ }^{[\mathrm{d}]}$ and M. Luisa Moyá ${ }^{[\mathrm{e}]}$
}

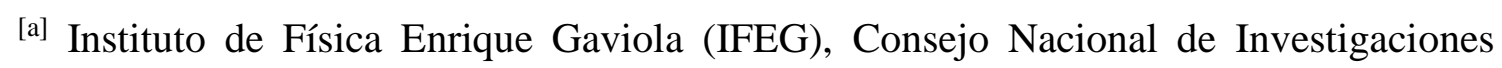
Científicas y Técnicas (CONICET) - Universidad Nacional de Córdoba (UNC), Medina Allende s/n, Ciudad Universitaria, X5016LAE Córdoba, Argentina.

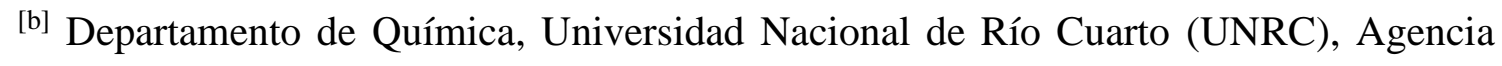
Postal \# 3, X5804BYA Río Cuarto, Argentina.

${ }^{[c]}$ Instituto para el Desarrollo Agroindustrial y de la Salud (IDAS), CONICET - UNRC. Agencia Postal \# 3, X5804BYA Río Cuarto, Argentina.

[d] Departamento de Ingeniería Química, Química Física y Ciencias de Materiales, Centro de Ciencia y Tecnología, Universidad de Huelva, Campus 'El Carmen', Facultad de Ciencias Experimentales, E-21071 Huelva, Spain.

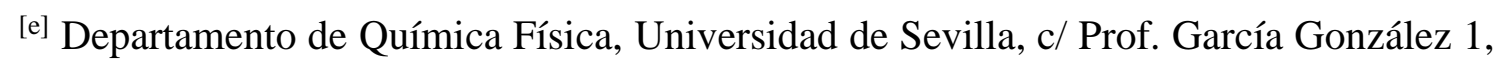
41012 Sevilla, Spain.

* Corresponding-Author: Dr. Cristian M. O. Lépori. E-mail: clepori@famaf.unc.edu.ar 


\begin{abstract}
The impact of the imidazolium counterions structure on the organized systems formed by the surfactant 1,4-bis-2-ethylhexylsulfosuccinate, AOT, both in aqueous solutions and in non-polar solvents is investigated. With this in mind, we investigated if the ionic liquid-like (IL-like) surfactant 1-ethyl-3-methylimidazolium 1,4-bis-2ethylhexylsulfosuccinate, emim-AOT, forms direct micelles or vesicles in water. Dynamic Light Scattering (DLS), zeta potential, conductivity, fluorescence and UVVisible spectroscopy measurements were performed to characterize the organized systems in aqueous solution. We also studied the self-aggregation of emim-AOT, 1butyl-3-methylimidazolium 1,4-bis-2-ethylhexylsulfosuccinate, bmim-AOT, and of 1hexyl-3-methylimidazolium 1,4-bis-2-ethylhexylsulfosuccinate, hmim-AOT, in nonpolar solvents.

The results obtained showed that the IL-like surfactant emim-AOT forms direct micelles in water, as Na-AOT does. However, emim-AOT aggregates are larger, have a lower surface charge, are more stable, and have a more polar and less fluid micellar interface than Na-AOT micelles. It was also observed that emim-AOT and hmim-AOT form reverse micelles in non-polar solvents. The size of the imidazolium cations dramatically influences on the size of the reverse micelles as well as on their ability to solubilize water.
\end{abstract}

KEYWORDS: ionic liquid-like surfactant, organized systems, Na-AOT, emim-AOT. 


\section{INTRODUCTION}

Organized systems are important and promising in the progress of various branches of modern science and technology. ${ }^{1,2}$ For example, they are used as detergent, in the industries of dyes, cosmetic and pharmaceutical. ${ }^{3}$ The existence of different microenvironments in these systems is one of the reasons for their applications in different areas, such as chemical catalysis, ${ }^{4-8}$ enzymatic hydrolysis, ${ }^{9-12}$ and nanoparticle synthesis, ${ }^{13-16}$ among others. ${ }^{17}$ In this context, nanomedicine has become in recent years one of the most promising fields concerning the diverse applications of organized systems. For example, they are frequently used as drug delivery systems. ${ }^{718-21}$ Also, the biomimetic characteristics presented by these systems can be highlighted, since they can be considered "simplified models" that simulate the behavior of highly complex structures, such as biological membranes. ${ }^{22,23}$

The surfactant sodium 1,4-bis-2-ethylhexylsulfosuccinate (Na-AOT, Scheme 1) can form direct micelles in aqueous solution, ${ }^{24-26}$ with a critical micellar concentration value $\sim 10^{-3} \mathrm{M}^{27-30}$ These aggregates have been used as a dispersing medium for hydrophobic dyes in an aqueous medium, ${ }^{31}$ for the synthesis of nanoparticles, ${ }^{16,32}$ among others. ${ }^{33}$ Furthermore, reverse micelles formulated in non-polar organic solvents can be created using also Na-AOT as surfactant. Depending mostly on the non-polar organic medium and temperature, these systems have the ability to disperse large amounts of water. For example, it is possible to achieve a $\mathrm{W}_{0}{ }^{\max }=12$ using benzene, ${ }^{34}$ while in $n$-heptane is possible to reach a value close to $\mathrm{W}_{0}^{\max }=60^{35,36}\left(\mathrm{~W}_{0}=\right.$ [Water]/[Surfactant]). These properties are responsible for their numerous applications, as was mentioned above. ${ }^{4-6,9,11,13-15,17}$

Ionic Liquids (ILs) are synthetic compounds with interesting properties such as low toxicity, friendly to the environment and very versatile. ${ }^{37-39}$ Chemically, the ILs are 
salts with a low melting point $\left(<100{ }^{\circ} \mathrm{C}\right)$, composed only of ions. They also present very low vapor pressure, excellent thermal and chemical stability, easy recycling, and wide possibility to vary their properties such as polarity and hydrophobicity, through suitable cation and anion modification. ${ }^{40}$ In this sense, the possibility to create ILs with amphiphilic properties have been increased in the last years. ${ }^{41-43}$ These novels compounds, named IL-like surfactants, were able to formulate direct micelles, reverse micelles and vesicles as examples of organized systems. ${ }^{39,41-47}$ Furthermore, the IL-like surfactants derived from the imidazolium group are very interesting due to the unique properties of such cation: i) delocalization of the positive charge on the heterocyclic ring, which produce great stability. ii) The possibility of substituting the hydrogen attached to the carbon atom located between the two nitrogen atoms, for a substituent that allows the rest of the imidazolium ring to act as a ligand catalyst for metals. iii) Change the lipophilic character of the cation by substitution with alkyl groups at the ring nitrogen's. Besides, thinking in future applications such as the design of catalysts, the flat geometry of the imidazolium ring can also be a significant aspect to consider. ${ }^{48-}$ 50

Recently ${ }^{46,51}$ we reported the synthesis of two IL-like surfactants 1-butyl-3methylimidazolium 1,4-bis-2-ethylhexylsulfosuccinate and 1-hexyl-3methylimidazolium 1,4-bis-2-ethylhexylsulfosuccinate (bmim-AOT and hmim-AOT respectively, Scheme 1). In comparison with Na-AOT, these IL-like surfactants showed very different properties. ${ }^{46,51}$ Particularly, we studied the physicochemical properties of the aggregates formed by bmim-AOT and hmim-AOT in different solvents. ${ }^{46,47}$

Taking into account, the effect of the AOT counterion structure on the selfassembly process is investigated. With this goal, the IL-like surfactant 1-ethyl-3methylimidazolium 1,4-bis-2-ethylhexylsulfosuccinate (emim-AOT, Scheme 1) was 
synthesized. Later, the emim-AOT aqueous solutions were investigated performing several experiments in order to acquire information about size, surface charge, degree of dissociation, critical micellar concentration $(\mathrm{cmc})$, aggregation number $\left(\mathrm{N}_{\mathrm{agg}}\right)$, micropolarity and microviscosity. Thus, emim-AOT aggregates were investigated using Dynamic Light Scattering (DLS), zeta potential and conductivity techniques. Additionally, by using three molecular probes such as pyrene (Scheme S1, Supplementary Material), 2,2'-[[4-[(4-nitrophenyl)azo]phenyl]imino]bisethanol ${ }^{52-54}$ (DR9, Scheme S1) and 1,3-dipyrenylpropane ${ }^{55,56}$ (P3P, Scheme S1), valuable information about the $\mathrm{cmc}, \mathrm{N}_{\mathrm{agg}},{ }^{57,58}$ polarity and viscosity of their microenvironment can be obtained. ${ }^{58,59}$ The self-association of emim-AOT and hmim-AOT in the nonpolar solvents $n$-heptane and benzene was examined and the results compared with those already reported on reverse micelles of bmim-AOT and Na-AOT. ${ }^{46,47,60}$
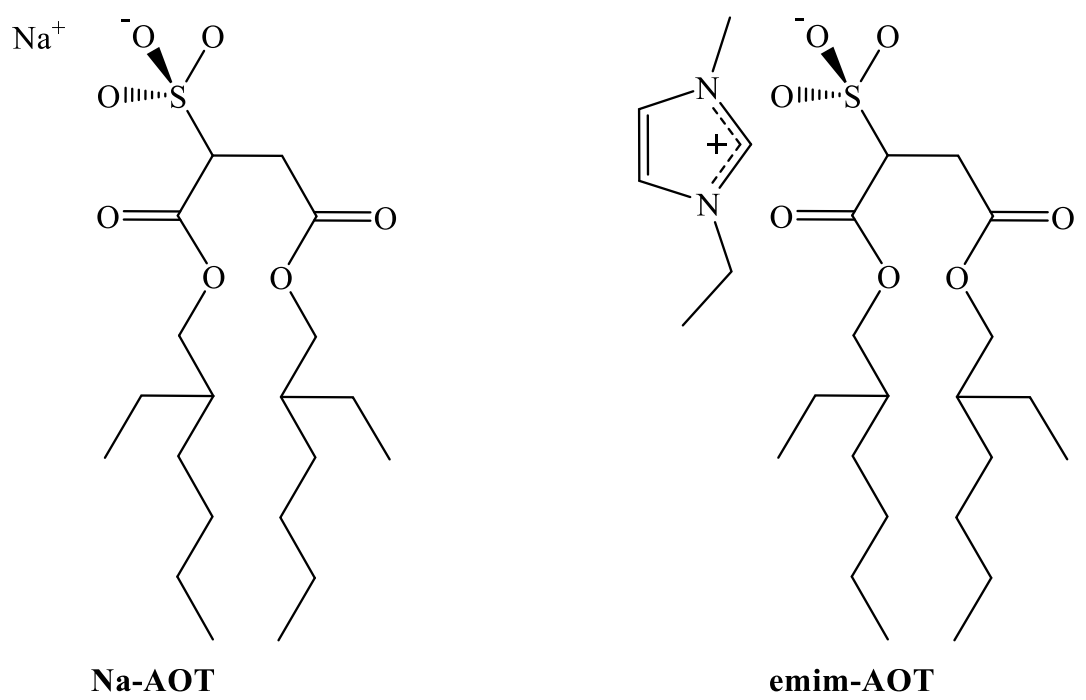

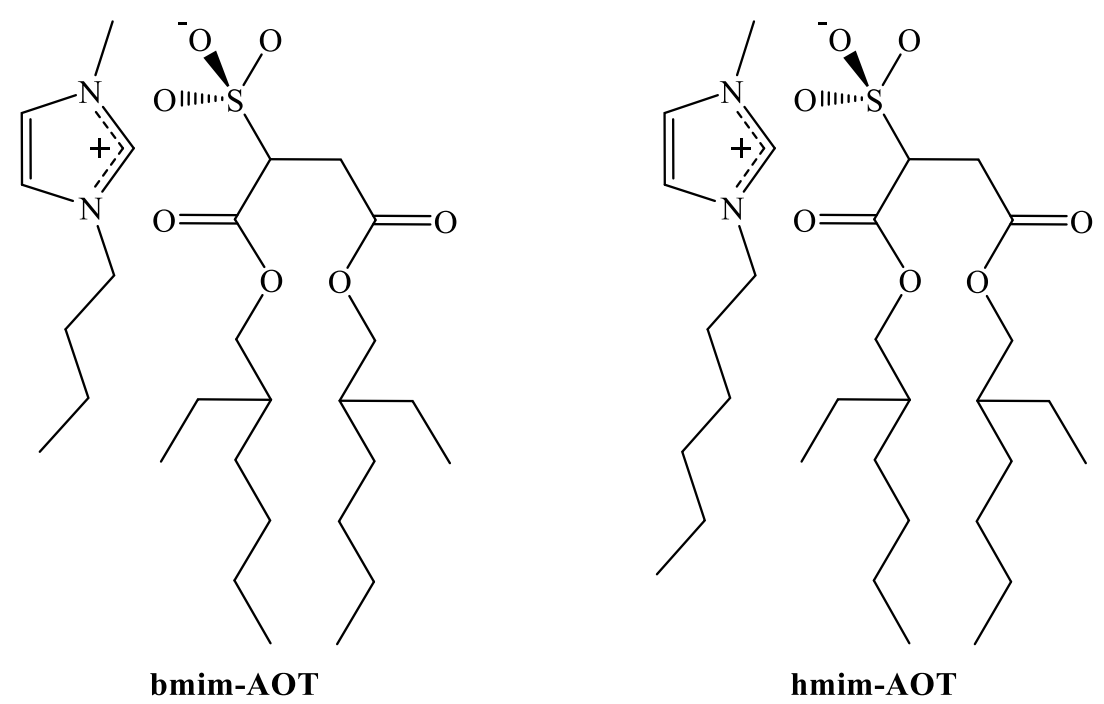

Scheme 1. Molecular structures of the surfactants Na-AOT, emim-AOT, bmim-AOT and hmim-AOT.

\section{EXPERIMENTAL SECTION}

\section{Materials}

1-Ethyl-3-methylimidazolium chloride (emim-Cl), bmim-Cl, hmim-Cl, NaAOT, dichloromethane (DCM), benzene, $n$-heptane, $N$-hexadecylpyridinium bromide $(\mathrm{CPyBr})$ and DR19 were from Sigma-Aldrich (> 99\% purity) and kept under vacuum prior to use. P3P and pyrene were purchased from Molecular Probes, Inc. and used as received.

The IL-like surfactants used, bmim-AOT and hmim-AOT, were obtained following the experimental procedures previously described. ${ }^{46,51}$ Emim-AOT was prepared following the same methodology (fully described in Supplementary Material section), ${ }^{46,51}$ using as reactants emim-Cl and Na-AOT.

\section{Methods}

Detailed experimental procedure for all the samples preparations; DLS, zeta potential, conductivity and emission experiments are shown in the Supplementary Material 
section.

\section{RESULTS AND DISCUSSION}

As a first experiment, the solubility of emim-AOT in water was investigated. This IL-like surfactant was soluble in water until $2 \times 10^{-2} \mathrm{M}$, forming transparent solutions which remain stable over time. Similar behavior was reported by the Na-AOT surfactant and can suggests the formation of small size aggregates with low capacity to scatter the light. ${ }^{61}$

We previously observed by DLS that the surfactants bmim-AOT and hmimAOT form vesicles in water. ${ }^{51}$ In this work aqueous solutions of emim-AOT in water were prepared, in a concentration range from $1 \times 10^{-4} \mathrm{M}$ to $2 \times 10^{-2} \mathrm{M}$, and the samples were analyzed by DLS. Table 1 shows the apparent hydrodynamic diameter, $\mathrm{d}_{\mathrm{app}}$, values obtained for emim-AOT in water at 298 K. In Figure S3 (Supplementary Material), the DLS intensity plot for emim-AOT in water at [surfactant $]=1 \times 10^{-2} \mathrm{M}$ is depicted. The DLS data show the formation of aggregates with diameters ranging from $1.2-1.4 \mathrm{~nm}$, with low polydispersity indexes (within the range $0.1-0.2$ ). Moreover, within the range of $6 \times 10^{-3} \mathrm{M}-2 \times 10^{-2} \mathrm{M}$ the sizes were independent of the surfactant concentration. The sizes found for the emim-AOT aggregates and the detection of these aggregates from $[\mathrm{emim}-\mathrm{AOT}]=6 \times 10^{-3} \mathrm{M}$, are good evidences that the surfactant self-aggregates forming direct micelles, ${ }^{23}$ as makes the surfactant Na-AOT. ${ }^{25,26,28}$ The DLS results seem to indicate that the critical micellar concentration is close to $6 \times 10^{-3} \mathrm{M} .^{23}$ 
Table 1. $d_{a p p}$ and polydispersity indexes (PDI) values of emim-AOT micelles in water at different surfactant concentrations. $\mathrm{T}=298 \mathrm{~K}$.

\begin{tabular}{ccc}
\hline [Surfactant] $\left.\mathbf{( 1 0}^{-\mathbf{2}} \mathbf{M}\right)$ & $\mathbf{d}_{\text {app }} \mathbf{( n m )}$ & PDI \\
\hline 0.6 & $1.4 \pm 0.1$ & 0.2 \\
0.8 & $1.3 \pm 0.1$ & 0.2 \\
1.0 & $1.3 \pm 0.1$ & 0.2 \\
1.2 & $1.2 \pm 0.1$ & 0.1 \\
1.6 & $1.3 \pm 0.1$ & 0.1 \\
2.0 & $1.3 \pm 0.1$ & 0.1 \\
\hline
\end{tabular}

Zeta potential measurements were carried out to determine the surface charge of these aggregates and the corresponding values are listed in Table 2.

Table 2. Zeta potential values $(\mathrm{mV})$ of Na-AOT and emim-AOT micelles in water at different surfactant concentrations. $\mathrm{T}=298 \mathrm{~K}$.

\begin{tabular}{ccc}
\hline [Surfactant] $\left(\mathbf{1 0}^{-\mathbf{2}} \mathbf{M}\right)$ & Na-AOT & emim-AOT \\
\hline 0.6 & $-51 \pm 2$ & $-37 \pm 2$ \\
0.8 & $-52 \pm 2$ & $-36 \pm 2$ \\
1.0 & $-49 \pm 2$ & $-38 \pm 2$ \\
1.2 & $-51 \pm 2$ & $-37 \pm 2$ \\
1.6 & $-52 \pm 2$ & $-40 \pm 2$ \\
2.0 & $-50 \pm 2$ & $-39 \pm 2$ \\
\hline
\end{tabular}

Data in Table 2 show zeta potential values of $-51 \mathrm{mV}$ and $-38 \mathrm{mV}$ for micelles of Na-AOT and emim-AOT, respectively. Thus, the anionic part of the polar head of 
both surfactants appears to be exposed to the outer region of the micelle in both cases. However, the larger zeta potential value found for Na-AOT micelles compared to emim-AOT micelles could indicate the presence of a smaller concentration of positive counterions in the micellar interface of the water/Na-AOT systems than in the emimAOT aggregates. This may due to the $\mathrm{emim}^{+}$cation which is more hydrophobic than the $\mathrm{Na}^{+}$cation, and therefore it prefers to be part of the micellar aggregate than to be solvated in the aqueous phase. To check this effect, the degree of counterion dissociation of micelles, $\alpha,{ }^{62}$ of emim-AOT and Na-AOT was determined by measuring the conductivity of the medium at different concentrations of surfactant, as shown in Figure 1 and Figure S3 (Supplementary Material), respectively.

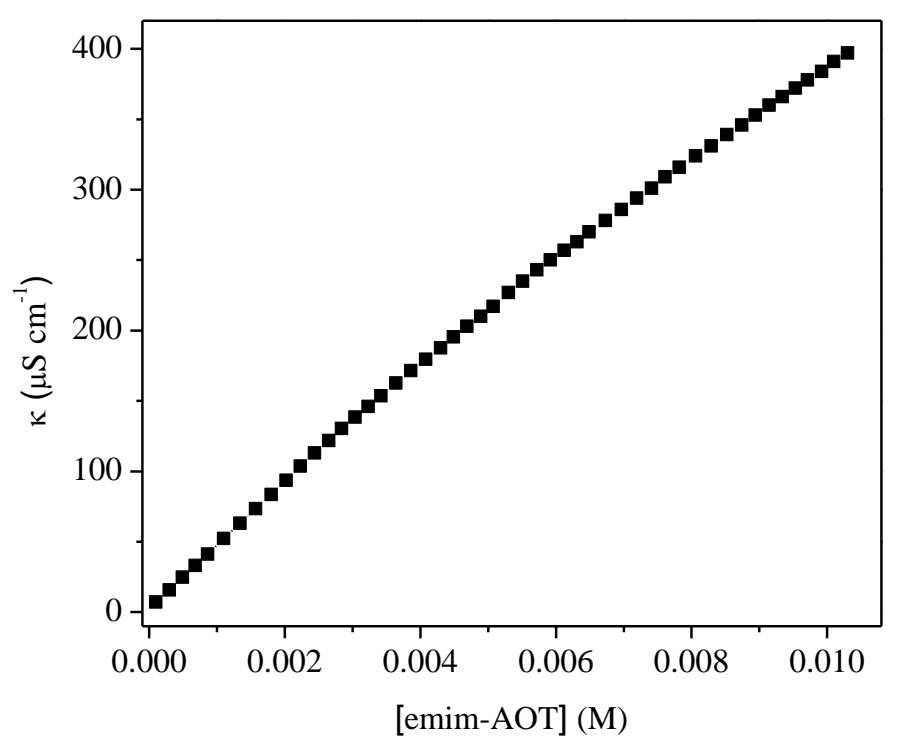

Figure 1. Variation of the conductivity with [surfactant] in the micellar system water/emim-AOT. T $=298 \mathrm{~K}$.

The $\alpha$ values were determined using the method described by Carpena et al. ${ }^{62}$ Thus, we found for emim-AOT direct micelles a value of $\alpha=0.73$, while for the NaAOT micellar system is $\alpha=0.92$. These results show that the emim ${ }^{+}$counterion, in the 
emim-AOT direct micelles, is bound to the $\mathrm{AOT}^{-}$head groups more extensively than the $\mathrm{Na}^{+}$counterion in the Na-AOT micelles. In the latter, the $\mathrm{Na}^{+}$ions can be considered practically dissociated from the micelles in aqueous solution. These results agree with the data obtained by zeta potential.

The method described by Carpena et al. ${ }^{62}$ also permits the estimation of cmc values. The cmc values obtained were $2.5 \times 10^{-3} \mathrm{M}$ and $3.3 \times 10^{-3} \mathrm{M}$ for emim-AOT and Na-AOT, respectively. The Na-AOT cmc value has already been reported ${ }^{30}$ and our determination agrees with this value. Nonetheless, to further investigate this point, the cmc's of both systems were estimated through fluorescence spectroscopy using pyrene as probe. Pyrene was used at a fixed concentration, varying the surfactant concentration from $5 \times 10^{-4} \mathrm{M}$ to $1 \times 10^{-2} \mathrm{M}$. The ratio of the intensity of peaks $3\left(\mathrm{I}_{3}\right)$ and $1\left(\mathrm{I}_{1}\right)$ in the fluorescence spectrum of the pyrene was plotted, as a function of $\log$ [surfactant] for emim-AOT and Na-AOT micellar systems, as shown in Figures 2 and S4 (Supplementary Material), respectively.

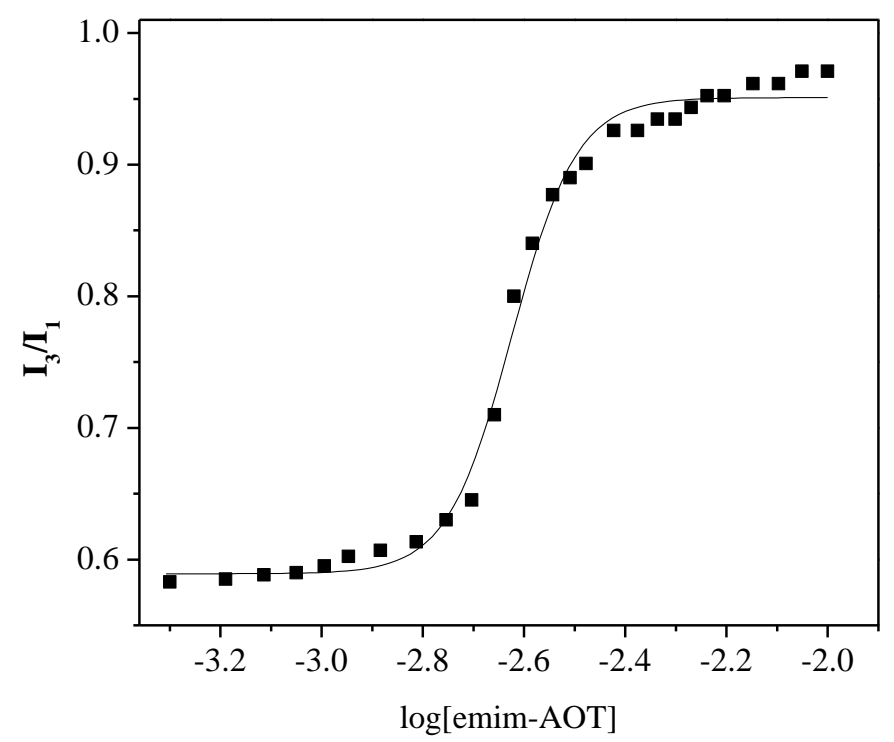

Figure 2. Dependence of the $I_{3} / I_{1}$ ratio on $\log$ [surfactant] in emim-AOT aqueous solutions. $[$ Pyrene $]=1 \times 10^{-6} \mathrm{M} . \mathrm{T}=298 \mathrm{~K}$. 
By this methodology, the cmc value for emim-AOT micelles is $2.3 \times 10^{-3} \mathrm{M}$, while for Na-AOT micellar system it is $3.0 \times 10^{-3} \mathrm{M}$. Both values are in agreement with those obtained by conductivity measurements. From the $\alpha$ and cmc values, the Gibbs energy of micellization, $\Delta \mathrm{G}_{\mathrm{mic}}$, can be calculated by using Equation $1:^{63}$

$$
\Delta \mathrm{G}^{\circ}{ }_{\mathrm{M}}=\mathrm{RT}(2-\alpha) \ln (\mathrm{cmc})
$$

where $\mathrm{R}$ and $\mathrm{T}$ have their usual meaning. $\Delta \mathrm{G}^{\circ}{ }_{\mathrm{M}}$ values are summarized in Table 3.

Table 3. Critical micelle concentration (cmc), micellar ionization degree $(\alpha)$ and Gibbs energy of micellization $\left(\Delta \mathrm{G}^{\circ}{ }_{\mathrm{M}}\right)$ for the emim-AOT and Na-AOT surfactants in water. $\mathrm{T}$ $=298 \mathrm{~K}$.

\begin{tabular}{cccc}
\hline Surfactant & $\boldsymbol{\alpha}$ & $\begin{array}{c}\mathbf{c m c} \\
(\mathbf{m M})\end{array}$ & $\begin{array}{c}\Delta \mathbf{G}^{\circ} \mathbf{M} \\
\left(\mathbf{k J ~ m o l}^{\mathbf{1}} \mathbf{)}\right.\end{array}$ \\
\hline emim-AOT & $0.73 \pm 0.02$ & $2.3 \pm 0.2$ & -19.2 \\
Na-AOT & $0.92 \pm 0.02$ & $3.0 \pm 0.2$ & -15.5 \\
\hline
\end{tabular}

Analyzing the data in Table 3 , it can be seen that the micellization process of emim-AOT micelles is more favored than that of Na-AOT micelles. This could be explained by considering the more hydrophobic character of the $\mathrm{emim}^{+}$cation as compared to $\mathrm{Na}^{+}$.

The $\mathrm{N}_{\mathrm{agg}}$ of emim-AOT micelles was determined, using pyrene and $\mathrm{CPyBr}$, as a quencher. In the experiments the quencher concentration was changed while the surfactant and pyrene concentrations were kept constant at $1 \times 10^{-2} \mathrm{M}$ and $1 \times 10^{-6} \mathrm{M}$, respectively. The $N_{a g g}$ value was obtained from the slope of the plot of $\ln \left(I_{0} / I_{q}\right)$ vs. $[\mathrm{CPyBr}]$, as shown in Figure 4 , where $\mathrm{I}_{0}$ and $\mathrm{I}_{\mathrm{q}}$ are the intensity of the pyrene peak 1 in the absence and in the presence of the quencher, respectively, as was previously 
described..$^{30}$

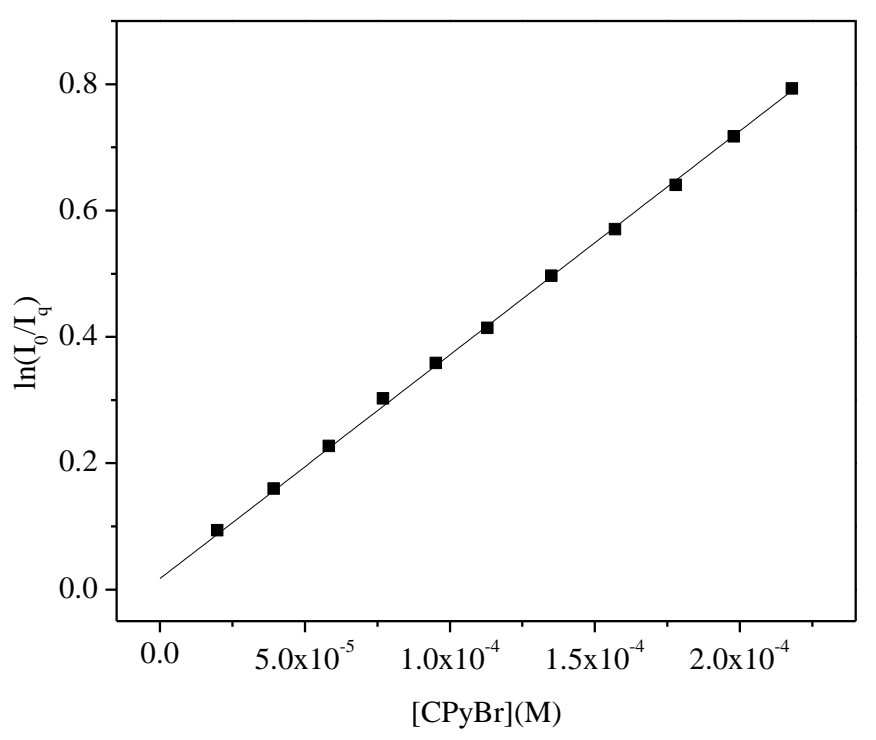

Figure 3. Variation of the $\ln \left(\mathrm{I}_{0} / \mathrm{I}_{\mathrm{q}}\right)$ with $[\mathrm{CPyBr}]$ in the micellar system water/emimAOT. $[$ emim-AOT $]=1 \times 10^{-2} \mathrm{M} .[$ Pyrene $]=1 \times 10^{-6} \mathrm{M} . \mathrm{T}=298 \mathrm{~K}$.

The $\mathrm{N}_{\text {agg }}$ value calculated from Figure 3 for emim-AOT direct micelles is 28 . This value seems reasonable since the $\mathrm{N}_{\text {agg }}$ reported in the bibliography for Na-AOT is $22 .{ }^{30}$ Since the $\alpha$ value of emim-AOT is lower than that of Na-AOT, this could indicate that there is a greater presence of the emim ${ }^{+}$counterions in the micellar interface, thus decreasing the electrostatic repulsions between the AOT $^{-}$negatively charged heads.

The interfacial microviscosity of these organized systems is also interesting information to explore. To do that, the probe P3P was employed ([P3P] $\left.=2 \times 10^{-6} \mathrm{M}\right)$ and the [surfactant] was varied. The dependence of the ratio $\mathrm{I}_{\mathrm{M}} / \mathrm{I}_{\mathrm{E}}$ on [Surfactant], $\mathrm{I}_{\mathrm{M}}$ and $\mathrm{I}_{\mathrm{E}}$ being the intensities of the emission bands of the monomer and of the excimer of the probe, respectively, can provide this information. ${ }^{56}$ As it is presented in Figure 4, an increase in the microviscosity of the environment (where the molecular probe is located) can be invoked if an increment in the $\mathrm{I}_{\mathrm{M}} / \mathrm{I}_{\mathrm{E}}$ ratio is observed. ${ }^{55,58,64}$ In both systems, a 
sigmoidal tendency in the $\mathrm{I}_{\mathrm{M}} / \mathrm{I}_{\mathrm{E}}$ ratio is observed. Moreover, for all the surfactant concentrations investigated a higher ratio for emim-AOT in comparison with Na-AOT was found. This fact would suggest a larger rigidity of the micellar interface of emimAOT micelles than that of the Na-AOT aggregates.

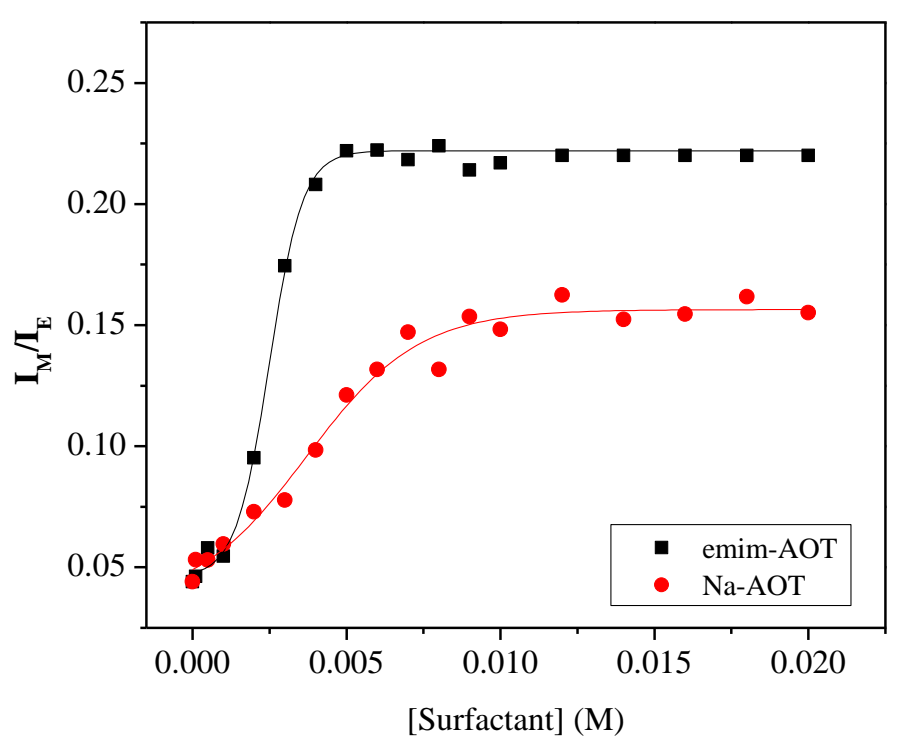

Figure 4. Values of $I_{M} / I_{E}$ ratio as a function of [surfactant] in the micellar systems water/Na-AOT and water/emim-AOT. $[\mathrm{P} 3 \mathrm{P}]=2 \times 10^{-6} \mathrm{M} . \mathrm{T}=298 \mathrm{~K}$.

Results in Figure 4 indicate a higher viscosity for the emim-AOT micellar interface than that for Na-AOT. This agrees with the results obtained so far, since the emim-AOT micelles have a higher $\mathrm{N}_{\text {agg }}$ and a lower $\alpha$ than Na-AOT aggregates. A higher concentration of $\mathrm{emim}^{+}$in the micellar interface results in a lower solvent penetration in this region, thus generating a more compact micelle with a higher viscosity.

Direct micelles have the potential to solubilize hydrophobic compounds in water ${ }^{65-69}$ For this reason, the ability of both micelles to incorporate a water-insoluble molecule such as the DR19 dye ${ }^{52-54}$ was tested. Thus, the amount of DR19 dissolved in 
both micellar solutions by varying the [surfactant] is plotted in Figure 5.

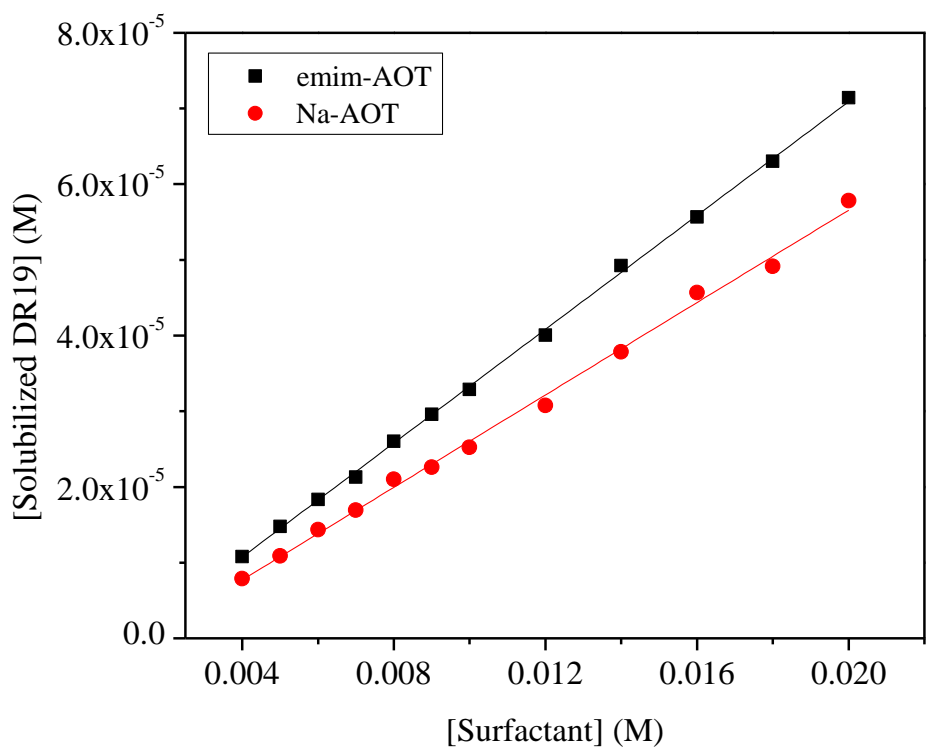

Figure 5. Amount of DR19 solubilized by the micellar systems water/Na-AOT and water/emim-AOT as a function of the [surfactant]. T $=298 \mathrm{~K}$.

As can be seen in Figure 5, the emim-AOT micelles solubilize a higher concentration of DR19 than the Na-AOT ones. This points out that the emim-AOT micelles might be less polar than the Na-AOT micelles, which could be because emim ${ }^{+}$ has a lower charge/volume ratio than the cation $\mathrm{Na}^{+}$. Besides, emim ${ }^{+}$has a methyl and an ethyl group as substituent of the ring nitrogen's, creating a more hydrophobic environment in the interface.

The compactness of the interface and consequently the size of the micelles can be interpreted invoking the effective packaging parameter of the surfactant $p$, which is defined as $p=v / a l_{c}$, where $v$ and $l_{c}$ are the volume and the length of the hydrocarbon chain, respectively, and $a$ is the area of the surfactant head group. ${ }^{70}$ In general, for direct micelles is $p<1 / 3$, vesicles present $1 / 2<p<1$, and bilayers $p \approx 1 .^{71}$ The size of the micelles is larger when the $p$ value is closer to $1 / 3$. Therefore, all factors that increase 
the $v$ value and/or decrease the $a$ value, increase the packaging parameter that affects the size of the micelles. ${ }^{71}$ Based on the results obtained in this work and considering those obtained previously from the IL-like surfactants bmim-AOT and hmim-AOT in water, ${ }^{51}$ a similar reasoning can be applied. The IL-like surfactant emim-AOT forms direct micelles, like the Na-AOT surfactant, but larger because of the substitution of the $\mathrm{Na}^{+}$counterion by emim ${ }^{+}$. The emim ${ }^{+}$counterion has alkyl groups that could be located near to the hydrocarbon tails of AOT, which favors hydrophobic interactions. In this way, the $p$ value would increase, but not exceeding $1 / 3$, since the hydrocarbon tail that has the emim ${ }^{+}$counterion is shorter than those of $\mathrm{bmim}^{+}$and $\mathrm{hmim}^{+}$counterions in the analogous bmim-AOT and hmim-AOT surfactants. The latter have a $p$ value between $1 / 2$ and 1 , so they form vesicles in water. ${ }^{51}$ In Scheme 2 is postulated the ions distribution around the interface in both micelles. 
A

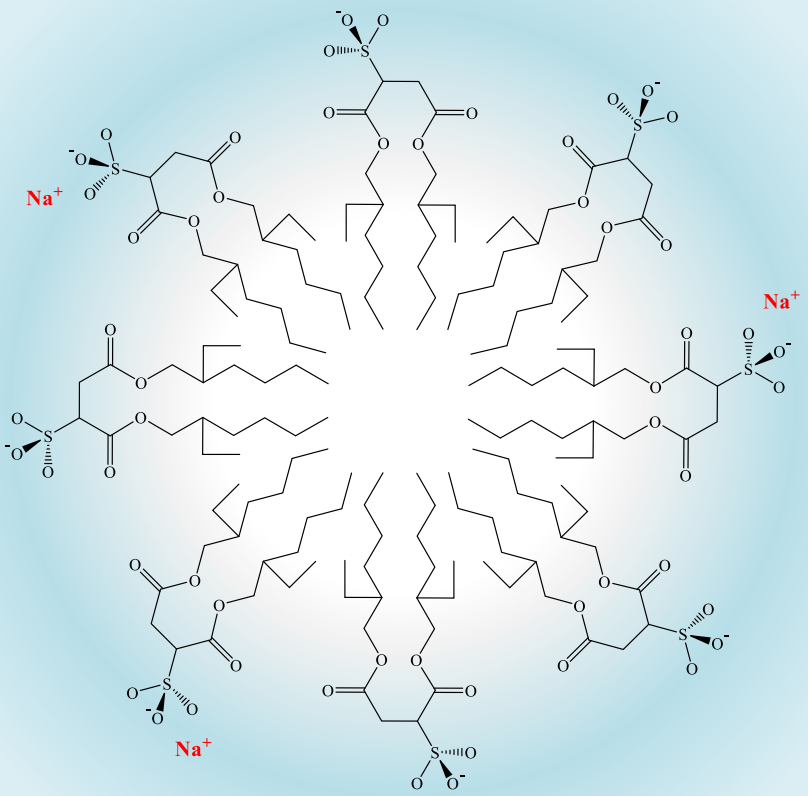

B

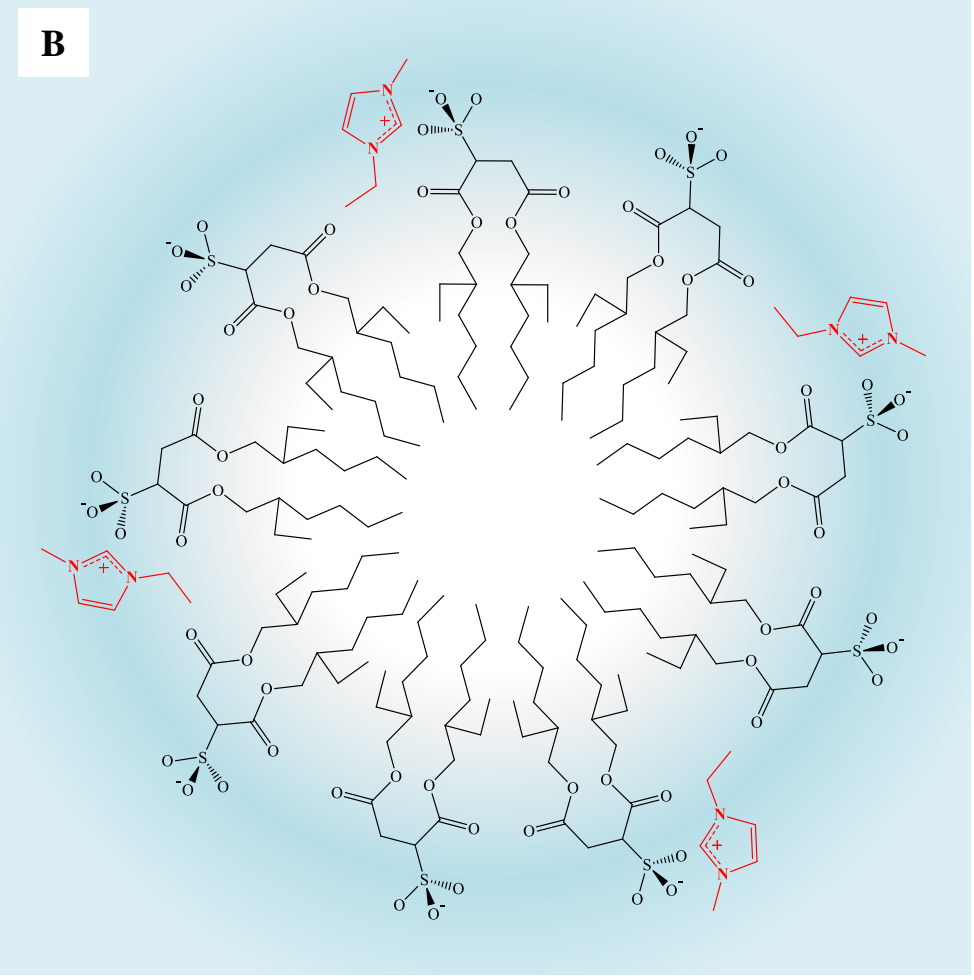

Scheme 2. Schematic representation of the direct micelles of Na-AOT surfactant (A) and IL-like surfactant emim-AOT (B). 
Considering that Na-AOT and emim-AOT form direct micelles, while bmimAOT and hmim-AOT form vesicles in water, the counterion nature has a clear influence on the type of aggregates formed in aqueous solution. With this in mind, information about the effect of the counterion on the self-aggregation of the IL-surfactants in nonpolar solvents was also investigated. Na-AOT and bmim-AOT form reverse micelles in these media and present several differences. ${ }^{46,47}$ Therefore, our interest was focused in the study of the self-aggregation of emim-AOT and hmim-AOT in different non-polar solvents.

Firstly, non-polar solvents such as benzene and $n$-heptane were selected to evaluate the solubility of emim-AOT and hmim-AOT. Emim-AOT was soluble at least up to $0.1 \mathrm{M}$ in benzene, but not in $n$-heptane, whereas hmim-AOT was soluble in both solvents. Next, water aliquots were added to the surfactants/non-polar solutions in order to investigate the maximal amount of polar solvent $\left(\mathrm{W}_{0}{ }^{\mathrm{max}}\right)$ able to be dissolved. In Table 4 the results obtained in all the systems evaluated that provide clear and stable ternary mixtures at [surfactant $]=0.1 \mathrm{M}$ is summarized. Additionally, the results found in Na-AOT and bmim-AOT micellar systems are also included.

Table 4. Values of $\mathrm{W}_{0}{ }^{\max }$ obtained in different systems at [surfactant] $=0.1 \mathrm{M} . \mathrm{T}=298$ K.

$\mathbf{W}_{0}{ }^{\text {max }}$

\begin{tabular}{ccccc} 
Non-polar solvent & Na-AOT $^{\mathbf{a}}$ & emim-AOT & bmim-AOT $^{\mathbf{b}}$ & hmim-AOT $^{\text {hmim }}$ \\
\cline { 2 - 5 } -Heptane & 60 & - & - & 14 \\
Benzene & 12 & 11 & 5 & 2
\end{tabular}

${ }^{\mathrm{a}}$ Value obtained from ref. $60{ }^{\mathrm{b}}$ Value obtained from ref. 46. 
As can be seen in Table 4, the values of $\mathrm{W}_{0}{ }^{\max }$ depends on the surfactant used. This result indicates that the counterion nature considerably influences the amount of solubilized water. For benzene/surfactant systems it can be seen that $\mathrm{W}_{0}{ }^{\max }$ decreases with increasing the hydrocarbon tail length of the imidazolium counterion, while in the $n$-heptane/surfactant micellar systems at a [surfactant] $=0.1 \mathrm{M}$, only the IL-like surfactant hmim-AOT can dissolve water. The $\mathrm{hmim}^{+}$counterion appears to act as a kind of co-surfactant. Therefore, the impact of the different counterions (imidazolium vs $\mathrm{Na}^{+}$) on properties such as the size or the interactions of water molecules at the interface is interesting to explore.

The solutions consisting of benzene/emim-AOT/water, benzene/hmimAOT/water and $n$-heptane/hmim-AOT/water were studied by the DLS technique in order to investigate the formation of reverse micelles. Table 5 shows the $d_{\text {app }}$ and PDI values of the DLS experiments that were performed at a surfactant concentration of 0.1 $\mathrm{M}$ for the emim-AOT and hmim-AOT solutions in non-polar solvents at $\mathrm{W}_{0}=5$. These working conditions were chosen to compare the data obtained in this work with those corresponding to the micellar systems formed by Na-AOT and bmim-AOT in the same solvents. ${ }^{46,47}$ It should be noted that the $d_{\text {app }}$ value of the benzene/hmim-AOT/water system was performed at $\mathrm{W}_{0}=2$, since this micellar system does not allow to prepare homogenous solutions at $\mathrm{W}_{0}$ larger than this value (Table 4). 
Table 5. Apparent hydrodynamic diameters $\left(\mathrm{d}_{\mathrm{app}}\right)$ and polydispersity indexes (PDI) for the benzene/surfactant/water and $n$-heptane/surfactant/water reverse micelles at $\mathrm{W}_{0}=5$. $\mathrm{T}=298 \mathrm{~K}$.

\begin{tabular}{ccccc}
\hline \multirow{2}{*}{ Surfactant } & \multicolumn{2}{c}{ benzene } & \multicolumn{2}{c}{-heptane } \\
\cline { 2 - 5 } & $\mathbf{d}_{\text {app }}(\mathbf{n m})$ & PDI & $\mathbf{d}_{\text {app }}(\mathbf{n m})$ & PDI \\
\hline Na-AOT & $2.9 \pm 0.3^{\mathrm{a}}$ & 0.05 & $5.1 \pm 0.1^{\mathrm{a}}$ & 0.05 \\
\hline emim-AOT & $3.5 \pm 0.2$ & 0.04 & - & - \\
\hline bmim-AOT & $3.9 \pm 0.2^{\mathrm{b}}$ & 0.03 & - & 0.01 \\
\hline hmim-AOT & $5.3 \pm 0.1^{\mathrm{c}}$ & 0.02 & $14.1 \pm 0.1$ & \\
\hline${ }^{\mathrm{a}}$ Value obtained from ref. $60 .^{\mathrm{b}}$ Value obtained from ref. $46 .{ }^{\mathrm{c}}$ Value at $\mathrm{W}_{0}=2$.
\end{tabular}

The apparent hydrodynamic diameter values listed in Table 5 make evident the existence of reverse micelles for emim-AOT and hmim-AOT surfactants in benzene. ${ }^{72,73}$ Furthermore, the low PDI values observed for the studied micellar systems suggest that the particles are essentially monodisperse. ${ }^{74}$

It is interesting to note that the $\mathrm{d}_{\text {app }}$ values of these IL-like surfactant micelles are higher than those of Na-AOT in benzene. Besides, the $d_{\text {app }}$ value is higher as the larger the size of the of imidazolium cation is. In this regard, it is interesting to consider that when the effective packaging parameter of the surfactant, $p$, diminishes, the diameter of reverse micelles increases. ${ }^{71}$ The values of $v$ and $l_{c}$ are similar for both the IL-like surfactants and Na-AOT. ${ }^{46}$ The substitution of $\mathrm{Na}^{+}$by the imidazolium cations can produce an increase in the $a$ value because the alkyl tails of the counterions would be close to the chains of AOT favoring the hydrophobic interactions and producing an increase in $\mathrm{d}_{\mathrm{app}}$.

Data in Table 5 show that the droplet sizes of the hmim-AOT reverse micelles 
are larger in $n$-heptane than in benzene. This result could be explained by considering the different penetration of the two non-polar solvents at the interface. It is well known that in Na-AOT reverse micelles, the penetration of the aromatic solvents into the interface is larger than aliphatic solvents. ${ }^{13,60}$ This phenomena can alter the $p$ value and, consequently, the sizes of reverse micelles. Thus, benzene penetrates deeper into the interfacial zone in Na-AOT reverse micelles than those of $n$-heptane. Consequently, at similar $\mathrm{W}_{0}$ value the Na-AOT/benzene reverse micelles are smaller than Na-AOT/nheptane reverse micelles. ${ }^{60}$ Furthermore, the micelle-micelle interactions and the water structure inside reverse micelles can be altered by the type or composition of the nonpolar phase. ${ }^{13,60}$ Thus, it was found that when aromatic solvents are used, inter-micellar interactions are weaker than in aliphatic solvents. As consequence of this fact, a notable impact on the practical applications of reverse micelles as nanoreactors can be produced. ${ }^{13,60}$ For example, in the synthesis of nanoparticles one of the key steps that controls the synthetic pathway is the coalescence process. In this sense, the inter-micelle interactions can be controlled by the nature of the non-polar solvent. ${ }^{75}$

\section{CONCLUSIONS}

Our investigations demonstrate that the substitution of $\mathrm{Na}^{+}$cation by alkylimidazolium cations on the AOT surfactant alter significantly the type and characteristics of the organized systems that they form, both in water and in non-polar solvents.

The IL-like surfactant emim-AOT forms direct micelles, while bmim-AOT and hmim-AOT can spontaneously form unilamellar vesicles in water, as previously shown. The emim-AOT micelles are larger, with less negative surface charge, a lower degree of ionization, and lower critical micellar concentration than those of Na-AOT. As a 
consequence, they have a higher Gibbs energy of micellization. Emim-AOT direct micelles also present a lower fluidity of the micellar interface and a greater capacity to solubilize low polarity molecules than Na-AOT ones.

In non-polar solvents emim-AOT forms reverse micelles in benzene, while hmim-AOT does in both benzene and $n$-heptane. It was observed that, depending on the imidazolium cation nature, the micellar systems have a different capacity to solubilize water in their interior and that the aggregates have different sizes.

These results show the importance of the surfactant counterion nature in the behavior of surfactants, converting them into ILs and determining the aggregates formed in the self-association process. Indeed, it is a very important factor to consider when designing new surfactants for different applications in which aggregates play a key role, such as drug nanocarriers, nanoreactors in the synthesis of nanoparticles or in different chemical reactions.

\section{ASSOCIATED CONTENT}

Supplementary Material. Full experimental methodology, molecular structures of the probes, NMR characterization of emim-AOT, DLS data of aqueous solution of emimAOT, conductivity measurements and determination of cmc with pyrene of Na-AOT aqueous solution, are available free of charge.

\section{AUTHOR INFORMATION}

Corresponding Author

*E-mail: clepori@,famaf.unc.edu.ar

\section{Notes}


The authors declare no competing financial interests.

\section{ACKNOWLEDGEMENTS}

We gratefully acknowledge the financial support for this work by the Consejería de Conocimiento, Investigación y Universidad de la Junta de Andalucía (P12-FQM1105), FQM-274, the Consejo Nacional de Investigaciones Científicas y Técnicas (PIP CONICET 112-2015-0100283), Universidad Nacional de Río Cuarto (PPI-UNRC 20162018, 2020-2024), Agencia Nacional de Promoción Científica y Técnica (PICT 20180508), and Ministerio de Ciencia y Tecnología, Gobierno de la Provincia de Córdoba (PID 2018). N.M.C., J.J.S. and R.D.F. hold a research position at CONICET. C.M.O.L. thanks CONICET for a research fellowship and Asociación Universitaria Iberoamericana de Postgrado (AUIP) and Consejería de Economía y Conocimiento de la Junta de Andalucía for a fellowship, with which Dr. Lépori made the research stay at the University of Seville (Spain).

\section{REFERENCES}

(1) Mclntire, G. L.; Dorsey, J. G. Critical Reviews in Analytical Chemistry Micelles in Analytical Chemistry Micelles in Analytical Chemistry. Crit. Rev. Anal. Chem. 1990, 21 (4), 257-278.

(2) Schwuger, M. J.; Stickdorn, K.; Schomäcker, R. Microemulsions in Technical Processes. Chem. Rev. 1995, 95 (4), 849-864.

(3) J. W. Steed, D. R. Turner, K. J. W. Core Concepts in Supramolecular Chemistry and Nanochemistry; John Wiley \& Sons, Ltd., 2007.

(4) Villa, C. C.; Correa, N. M.; Silber, J. J.; Falcone, R. D. Catanionic Reverse Micelles as an Optimal Microenvironment to Alter the Water Electron Donor 
Capacity in a SN2 Reaction. J. Org. Chem. 2019, 84 (3), 1185-1191.

(5) Blach, D.; Pessêgo, M.; Silber, J. J.; Correa, N. M.; García-Río, L.; Falcone, R.

D. Ionic Liquids Entrapped in Reverse Micelles as Nanoreactors for Bimolecular Nucleophilic Substitution Reaction. Effect of the Confinement on the Chloride Ion Availability. Langmuir 2014, 30 (41), 12130-12137.

(6) Crosio, M. A.; Correa, N. M.; Silber, J. J.; Falcone, R. D. A Protic Ionic Liquid, When Entrapped in Cationic Reverse Micelles, Can Be Used as a Suitable Solvent for a Bimolecular Nucleophilic Substitution Reaction. Org. Biomol. Chem. 2016, 14 (11), 3170-3177.

(7) Luna, M. A.; Gutierrez, J. A.; Cobo Solis, A. K.; Molina, P. G.; Correa, N. M. Vehiculization of Noscapine in Large Unilamellar Vesicles. Study of Its Protective Role against Lipid Peroxidation by Electrochemical Techniques. $J$. Electroanal. Chem. 2019, 833, 26-32.

(8) Cobo Solis, A. K.; Correa, N. M.; Molina, P. G. Electrochemical and Photophysical Behavior of 1-Naphthol in Benzyl-nHexadecyldimethylammonium 1,4-Bis (2-Ethylhexyl) Sulfosuccinate Large Unilamellar Vesicles. Phys. Chem. Chem. Phys. 2016, 18 (23), 15645-15653.

(9) Gomez Rodríguez, E. I.; Falcone, R. D.; Beassoni, P. R.; Moyano, F.; Correa, N. M. Supramolecular Systems as an Alternative for Enzymatic Degradation of 1Naphthyl Methylcarbamate (Carbaryl) Pesticide. ChemistrySelect 2019, 4 (24), 7204-7210.

(10) Cobo Solis, A. K.; Correa, N. M.; Molina, P. G. Determination of BenzylHexadecyldimethylammonium 1,4-Bis(2-Ethylhexyl) Sulfosuccinate Vesicles Permeability by Using Square Wave Voltammetry and an Enzymatic Reaction. Langmuir 2017, 33 (43), 12080-12086. 
(11) Durantini, A. M.; Falcone, R. D.; Silber, J. J.; Correa, N. M. Effect of Confinement on the Properties of Sequestered Mixed Polar Solvents: Enzymatic Catalysis in Nonaqueous 1,4-Bis-2-Ethylhexylsulfosuccinate Reverse Micelles. ChemPhysChem 2016, 17 (11), 1678-1685.

(12) Luna, M. A.; Silber, J. J.; Sereno, L.; Correa, N. M.; Moyano, F. Determining the Substrate Permeability through the Bilayer of Large Unilamellar Vesicles of DOPC. A Kinetic Study. RSC Adv. 2016, 6, 62594-62601.

(13) Gutierrez, J. A.; Alejandra Luna, M.; Mariano Correa, N.; Silber, J. J.; Darío Falcone, R. The Impact of the Polar Core Size and External Organic Media Composition on Micelle-Micelle Interactions: The Effect on Gold Nanoparticle Synthesis. New J. Chem. 2015, 39 (11), 8887-8895.

(14) Orellano, M. S.; Porporatto, C.; Silber, J. J.; Falcone, R. D.; Correa, N. M. AOT Reverse Micelles as Versatile Reaction Media for Chitosan Nanoparticles Synthesis. Carbohydr. Polym. 2017, 171, 85-93.

(15) Gutiérrez, J. A.; Caballero, S. J.; Díaz, L. A.; Guerrero, M. A.; Ruiz, J.; Ortiz, C. C. High Antifungal Activity against Candida Species of Monometallic and Bimetallic Nanoparticles Synthesized in Nanoreactors. ACS Biomater. Sci. Eng. 2018, 4 (2), 647-653.

(16) Mandal, S.; De, S. Copper Nanoparticles in AOT "Revisited”-Direct Micelles versus Reverse Micelles. Mater. Chem. Phys. 2016, 183, 410-421.

(17) Correa, N. M.; Silber, J. J.; Riter, R. E.; Levinger, N. E. Nonaqueous Polar Solvents in Reverse Micelle Systems. Chem. Rev. 2012, 112 (8), 4569-4602.

(18) Stagnoli, S.; Sosa Alderete, L.; Luna, M. A.; Agostini, E.; Falcone, R. D.; Niebylski, A. M.; Correa, N. M. Catanionic Nanocarriers as a Potential Vehicle for Insulin Delivery. Colloids Surfaces B Biointerfaces 2020, 188 (4), 110759. 
(19) Stagnoli, S.; Luna, M. A.; Villa, C. C.; Alustiza, F.; Niebylski, A.; Moyano, F.; Correa, N. M.; Falcone, R. D. Unique Catanionic Vesicles as a Potential "NanoTaxi” for Drug Delivery Systems. In Vitro and in Vivo Biocompatibility Evaluation. RSC Adv. 2017, 7 (9), 5372-5380.

(20) Pattni, B. S.; Chupin, V. V.; Torchilin, V. P. New Developments in Liposomal Drug Delivery. Chem. Rev. 2015, 115 (19), 10938-10966.

(21) Gaucher, G.; Satturwar, P.; Jones, M.-C.; Furtos, A.; Leroux, J.-C. Polymeric Micelles for Oral Drug Delivery. Eur. J. Pharm. Biopharm. 2010, 76 (2), 147158.

(22) Myers, D. Surfactant Science and Technology, 3rd ed.; John Wiley \& Sons, Inc., 2006.

(23) Fendler, J. H. Atomic and Molecular Clusters in Membrane Mimetic Chemistry. Chem. Rev. 1987, 87 (5), 877-899.

(24) Allen, F. J.; Truscott, C. L.; Gutfreund, P.; Welbourn, R. J. L.; Clarke, S. M. Potassium, Calcium, and Magnesium Bridging of AOT to Mica at Constant Ionic Strength. Langmuir 2019, 35 (17), 5753-5761.

(25) Dey, J.; Bhattacharjee, J.; Hassan, P. A.; Aswal, V. K.; Das, S.; Ismail, K. Micellar Shape Driven Counterion Binding. Small-Angle Neutron Scattering Study of AOT Micelle. Langmuir 2010, 26 (12), 15802-15806.

(26) Sheu, E. Y.; Chen, S.; John S. Huang. Structure and Growth of Bis(2-Ethylhexyl) Sulfosuccinate Micelles in Aqueous Solutions. J. Phys. Chem. 1987, 91 (12), $3306-3310$.

(27) Chatterjee, A.; Moulik, S. P.; Sanyal, S. K.; Mishra, B. K.; Puri, P. M. Thermodynamics of Micelle Formation of Ionic Surfactants: A Critical Assessment for Sodium Dodecyl Sulfate, Cetyl Pyridinium Chloride and Dioctyl 
Sulfosuccinate (Na Salt) by Microcalorimetric, Conductometric, and

Tensiometric Measurements. J. Phys. Chem. B 2001, 105 (51), 12823-12831.

(28) Brown, P.; Butts, C.; Dyer, R.; Eastoe, J.; Grillo, I.; Guittard, F.; Rogers, S.;

Heenan, R. Anionic Surfactants and Surfactant Ionic Liquids with Quaternary

Ammonium Counterions. Langmuir 2011, 27 (8), 4563-4571.

(29) Sheu, E. Y.; Lo Nostro, P.; Capuzzi, G.; Baglioni, P. Micelle and Microemulsion Properties of Cesium Di-Dodecyl-Dimethylsulfosuccinate, Cs-AOT. Langmuir 1999, 15 (20), 6671-6676.

(30) Umlong, I. M.; Ismail, K. Micellization of AOT in Aqueous Sodium Chloride, Sodium Acetate, Sodium Propionate, and Sodium Butyrate Media: A Case of Two Different Concentration Regions of Counterion Binding. J. Colloid Interface Sci. 2005, 291, 529-536.

(31) Rashid, T. U.; Kabir, S. M. F.; Biswas, M. C.; Bhuiyan, M. A. R. Sustainable Wastewater Treatment via Dye-Surfactant Interaction: A Critical Review. Ind. Eng. Chem. Res. 2020.

(32) Pinilla, A. M.; Blach, D.; Mendez, S. C.; Ortega, F. M. AOT Direct and Reverse Micelles as a Reaction Media for Anisotropic Silver Nanoparticles Functionalized with Folic Acid as a Photothermal Agent on HeLa Cells. SN Appl. Sci. 2019, 1, 858 .

(33) Sanchez, F.; Moya, M. L.; Rodrigues, A.; Jimenez, R.; Gomez-Herrera, C.; Yanes, C.; Lopez-Cornejo, P. Micellar, Microemulsion, and Salt Kinetic Effects upon the Reaction $\mathrm{Fe}(\mathrm{CN}) 2(\mathrm{Bpy}) 2$ + S2O82 -. Langmuir 1997, 2 (14), 30843089.

(34) Silber, J. J.; Biasutti, A.; Abuin, E.; Lissi, E. Interactions of Small Molecules with Reverse Micelles. Adv. Colloid Interface Sci. 1999, 82 (1-3), 189-252. 
(35) Hou, M. J.; Shah, D. O. Effects of the Molecular Structure of the Interface and Continuous Phase on Solubilization of Water in Water/Oil Microemulsions. Langmuir 1987, 3 (6), 1086-1096.

(36) Mohammad, A.; Inamuddin. Green Solvents II. Properties and Applications of Ionic Liquids; Springer, 2012.

(37) Hallett, J. P.; Welton, T. Room-Temperature Ionic Liquids: Solvents for Synthesis and Catalysis. 2. Chem. Rev. 2011, 111 (5), 3508-3576.

(38) Wasserscheid, P.; Welton, T. Ionic Liquids in Synthesis: Second Edition; WileyVCH Verlag GmbH \& Co. KGaA: Weinheim, Germany, 2008.

(39) Falcone, R. D.; Correa, N. M.; Silber, J. J.; Levinger, N. E. Ionic Liquids in Soft Confinement. In Ionic Liquid-Based Surfactant Science; John Wiley \& Sons, Inc: Hoboken, NJ, 2015; pp 283-301.

(40) Welton, T. Room-Temperature Ionic Liquids. Solvents for Synthesis and Catalysis. Chem. Rev. 1999, 99 (8), 2071-2083.

(41) Paul, B. K., Moulik, S. P. Ionic Liquid-Based Surfactant Science; John Wiley \& Sons, Inc: NJ, 2015.

(42) Villa, C. C.; Moyano, F.; Ceolin, M.; Silber, J. J.; Falcone, R. D.; Correa, N. M. A Unique Ionic Liquid with Amphiphilic Properties That Can Form Reverse Micelles and Spontaneous Unilamellar Vesicles. Chem. - A Eur. J. 2012, 18 (49), $15598-15601$.

(43) Lépori, C. M. O.; Silber, J. J.; Falcone, R. D.; Correa, N. M. Improvement of the Amphiphilic Properties of a Dialkyl Phosphate by Creation of a Protic Ionic Liquid-like Surfactant. RSC Adv. 2017, 7 (71), 44743-44750.

(44) Villa, C. C.; Correa, N. M.; Silber, J. J.; Moyano, F.; Falcone, R. D. Singularities in the Physicochemical Properties of Spontaneous AOT-BHD Unilamellar 
Vesicles in Comparison with DOPC Vesicles. Phys. Chem. Chem. Phys. 2015, 17 (26), 17112-17121.

(45) Villa, C. C.; Silber, J. J.; Correa, N. M.; Falcone, R. D. Effect of the Cationic Surfactant Moiety on the Structure of Water Entrapped in Two Catanionic Reverse Micelles Created from Ionic Liquid-Like Surfactants. ChemPhysChem 2014, 15 (14), 3097-3109.

(46) Lépori, C. M. O.; Correa, N. M.; Silber, J. J.; Falcone, R. D. How the Cation 1Butyl-3-Methylimidazolium Impacts the Interaction between the Entrapped Water and the Reverse Micelle Interface Created with an Ionic Liquid-like Surfactant. Soft Matter 2016, 12 (3), 830-844.

(47) Lépori, C. M. O. O.; Correa, N. M.; Silber, J. J.; Vaca Chávez, F.; Falcone, R. D. Interfacial Properties Modulated by the Water Confinement in Reverse Micelles Created by the Ionic Liquid-like Surfactant Bmim-AOT. Soft Matter 2019, 15 (5), 947-955.

(48) Zhao, Q.; Meng, G.; Nolan, S. P.; Szostak, M. N-Heterocyclic Carbene Complexes in C-H Activation Reactions. Chem. Rev. 2020, 120 (4), 1981-2048.

(49) Hapiot, P.; Lagrost, C. Electrochemical Reactivity in Room-Temperature Ionic Liquids. Chem. Rev. 2008, 108 (7), 2238-2264.

(50) Ventura, S. P. M.; E Silva, F. A.; Quental, M. V.; Mondal, D.; Freire, M. G.; Coutinho, J. A. P. Ionic-Liquid-Mediated Extraction and Separation Processes for Bioactive Compounds: Past, Present, and Future Trends. Chem. Rev. 2017, 117 (10), 6984-7052.

(51) Lépori, C. M. O.; Correa, N. M.; Silber, J. J.; Falcone, R. D.; López-López, M.; Moyá, M. L. Use of Ionic Liquids-like Surfactants for the Generation of Unilamellar Vesicles with Potential Applications in Biomedicine. Langmuir 
2019, 35 (41), 13332-13339.

(52) Menger, F. M.; Galloway, A. L. Contiguous versus Segmented Hydrophobicity in Micellar Systems. J. Am. Chem. Soc. 2004, 126 (48), 15883-15889.

(53) Jaggi, N.; Gin, M.; Yadav, K. Absorption and Fluorescence Spectra of Disperse Red 19-An Azo Dye. Indian J. Pure Appl. Phys. 2013, 51 (12), 833-836.

(54) Uliana, C. V.; Garbellini, G. S.; Yamanaka, H. Spectrophotometric Evaluation of the Behavior of Disperse Red 1 Dye in Aqueous Media and Its Interaction with Calf Thymus Ds-DNA. J. Braz. Chem. Soc. 2012, 23 (8), 1469-1475.

(55) Zana, R. Microviscosity of Aqueous Surfactant Micelles: Effect of Various Parameters. J. Phys. Chem. B 1999, 103 (43), 9117-9125.

(56) Kano, K.; Ishimura, T. Properties of Alkyl B-D-Glucoside and Alkyl b-DMaltoside Micelles. J. Chem. Soc. Perkin Trans. 2 Phys. Org. Chem. 1995, No. $8,1655-1660$.

(57) Martín, V. I.; Rodríguez, A.; Graciani, M. del M.; Robina, I.; Carmona, A.; Moyá, M. L. Physicochemical Characterization of Bromide Mono- and Dimeric Surfactants with Phenyl and Cyclohexyl Rings in the Head Group. J. Colloid Interface Sci. 2011, 363 (1), 284-294.

(58) Domínguez, R.; Rodríguez, A.; Maestre, A.; Robina, I.; Moyá, M. L. Synthesis and Physicochemical Characterization of Alkanedyil- $\alpha-\omega-$ Bis(Dimethyldodecylammonium) Bromide, 12-s-12,2Br-, Surfactants with $\mathrm{S}=7$, 9, 11 in Aqueous Medium. J. Colloid Interface Sci. 2012, 386 (1), 228-239.

(59) Martín, V. I.; de la Haba, R. R.; Ventosa, A.; Congiu, E.; Ortega-Calvo, J. J.; Moyá, M. L. Colloidal and Biological Properties of Cationic Single-Chain and Dimeric Surfactants. Colloids Surfaces B Biointerfaces 2014, 114, 247-254.

(60) Gutierrez, J. A.; Falcone, R. D.; Lopez-Quintela, M. A.; Buceta, D.; Silber, J. J.; 
Correa, N. M. On the Investigation of the Droplet-Droplet Interactions of Sodium 1,4-Bis(2-Ethylhexyl) Sulfosuccinate Reverse Micelles upon Changing the External Solvent Composition and Their Impact on Gold Nanoparticle Synthesis. Eur. J. Inorg. Chem. 2014, 2014 (27), 2095-2102.

(61) Berne, J. B.; Pecora, R. Dynamic Light Scattering with Applications to Chemistry,Biologyn and Physics; John Wiley \& Sons, 2000.

(62) Carpena, P.; Aguiar, J.; Bernaola-Galván, P.; Carnero Ruiz, C. Problems Associated with the Treatment of Conductivity-Concentration Data in Surfactant Solutions: Simulations and Experiments. Langmuir 2002, 18 (16), 6054-6058.

(63) Zana, R. Dimeric and Oligomeric Surfactants. Behavior at Interfaces and in Aqueous Solution: A Review. Adv. Colloid Interface Sci. 2002, 97, 205-253.

(64) Zana, R.; In, M.; Lévy, H.; Duportail, G. Alkanediyl- $\alpha, \omega-$ Bis(Dimethylalkylammonium Bromide). 7. Fluorescence Probing Studies of Micelle Micropolarity and Microviscosity. Langmuir 1997, 13 (21), 5552-5557.

(65) Moyá, M. L.; Rodríguez, A.; del Mar Graciani, M.; Fernández, G. Role of the Solvophobic Effect on Micellization. J. Colloid Interface Sci. 2007, 316 (2), $787-795$.

(66) Wang, P.; Shi, Q.; Shi, Y.; Clark, K. K.; Stucky, G. D.; Keller, A. A. Magnetic Permanently Confined Micelle Arrays for Treating Hydrophobic Organic Compound Contamination. J. Am. Chem. Soc. 2009, 131 (1), 182-188.

(67) Li, Z.; Lenk, T. I.; Yao, L. J.; Bates, F. S.; Lodge, T. P. Maintaining Hydrophobic Drug Supersaturation in a Micelle Corona Reservoir. Macromolecules 2018, 51 (2), 540-551.

(68) Fan, H.; Leve, E. W.; Scullin, C.; Gabaldon, J.; Tallant, D.; Bunge, S.; Boyle, T.; Wilson, M. C.; Brinker, C. J. Surfactant-Assisted Synthesis of Water-Soluble and 
Biocompatible Semiconductor Quantum Dot Micelles. Nano Lett. 2005, 5 (4), $645-648$.

(69) Laouini, A.; Koutroumanis, K. P.; Charcosset, C.; Georgiadou, S.; Fessi, H.; Holdich, R. G.; Vladisavljević, G. T. PH-Sensitive Micelles for Targeted Drug Delivery Prepared Using a Novel Membrane Contactor Method; 2013; Vol. 5.

(70) Cosgrove, T. Colloid Science Principles, Methods and Applications, 2nd ed.; John Wiley \& Sons, 2010.

(71) Ramanathan, M.; Shrestha, L. K.; Mori, T.; Ji, Q.; Hill, J. P.; Ariga, K. Amphiphile Nanoarchitectonics: From Basic Physical Chemistry to Advanced Applications. Phys. Chem. Chem. Phys. 2013, 15 (26), 10580-10610.

(72) Durantini, A. M.; Falcone, R. D.; Anunziata, J. D.; Silber, J. J.; Abuin, E. B.; Lissi, E. A.; Correa, N. M. An Interesting Case Where Water Behaves as a Unique Solvent. 4-Aminophthalimide Emission Profile to Monitor Aqueous Environment. J. Phys. Chem. B 2013, 117 (7), 2160-2168.

(73) Falcone, R. D.; Correa, N. M.; Silber, J. J. On the Formation of New Reverse Micelles: A Comparative Study of Benzene/Surfactants/Ionic Liquids Systems Using Uv-Visible Absorption Spectroscopy and Dynamic Light Scattering. Langmuir 2009, 25 (18), 10426-10429.

(74) Maitra, a. Determination of Size Parameters of Water Aerosol OT Oil Reverse Micelles From Their Nuclear Magnetic-Resonance Data. J. Phys. Chem. 1984, 88 (21), 5122-5125.

(75) Ganguli, A. K.; Ganguly, A.; Vaidya, S. Microemulsion-Based Synthesis of Nanocrystalline Materials. Chem. Soc. Rev. 2010, 39 (2), 474-485. 


\section{GRAPHICAL ABSTRACT}

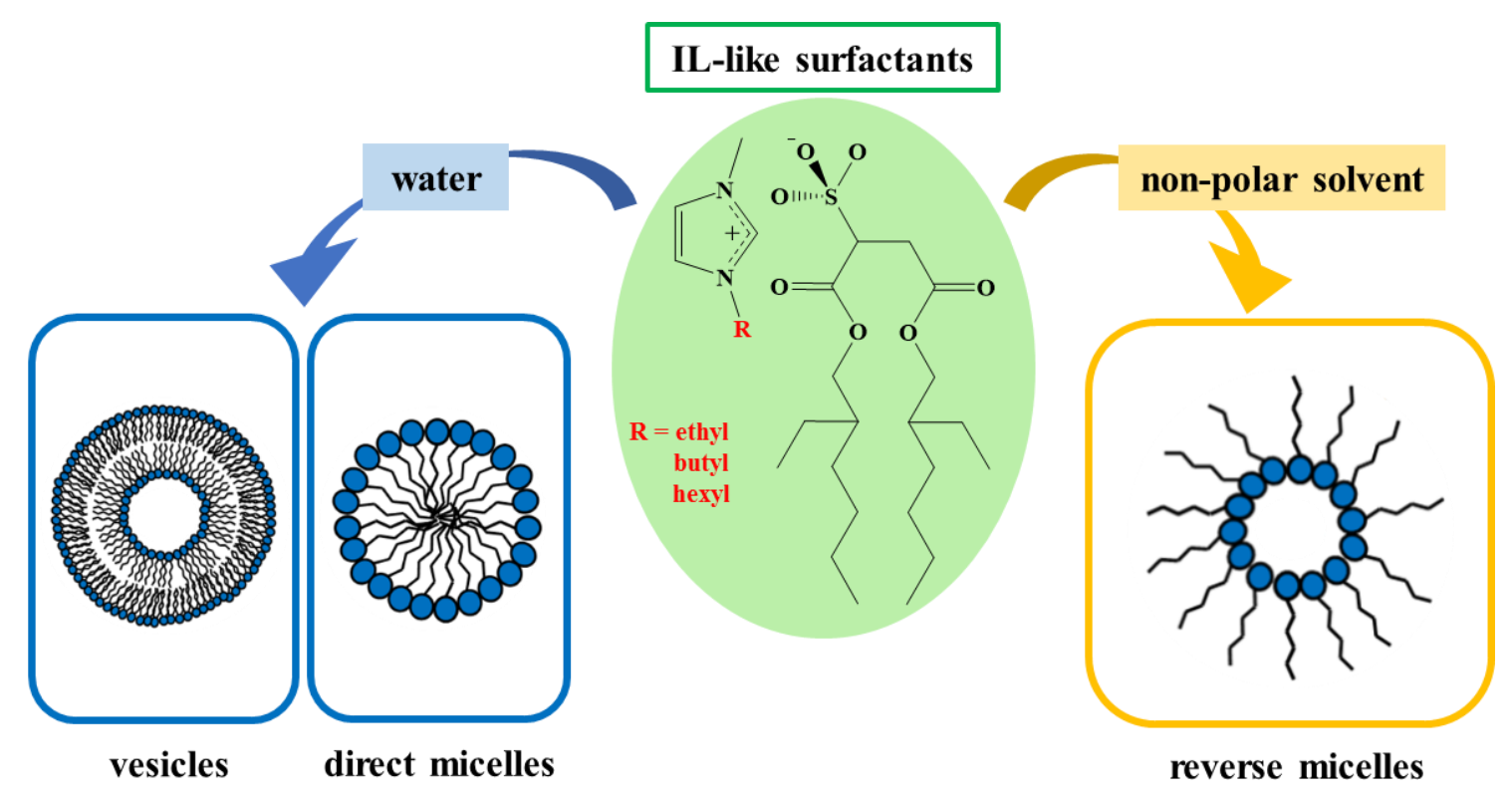

The IL-like surfactant emimAOT forms direct micelles in water, while bmimAOT and hmimAOT form vesicles in water. The three IL-like surfactants form reverse micelles in non-polar organic solvents. 